\title{
Familia, un espacio de tensiones para la Cultura de Paz
}

Luis Alfonso Guadarrama Rico²

$\mathbf{L}$

A Cultura de PAz ${ }^{3}$ es un eje temático que representa un desafio, pues recientemente los estudios multidisciplinarios en este campo han iniciado su incursión en distintas disciplinas. Los estudios sobre la Paz se han desarrollado vertiginosamente en Europa desde 1959, con las contribuciones y esfuerzos de Johan Galtung, fundador del Peace Research Institute en Oslo, Noruega. Quienes nos dedicamos a la investigación, en el ámbito de algún aspecto de la comunicación, estamos en desventaja debido a que en América Latina dichos estudios empiezan a emerger muy recientemente. ${ }^{4}$ Baste recordar que hasta hace muy poco fue dedicado un número de la Revista Diálogos al tema de la violencia mediática: la antítesis de la Paz es un punto fundamental para analizar qué sucede y cuáles son los retos para avanzar frontalmente hacia una cultura de paz.

Con pleno reconocimiento de que es dificil ponerse al tanto sobre las principales contribuciones y discusiones que hoy se fraguan en los estudios sobre la Paz, quiero colocar algunos puntos de partida en torno a lo que entiendo por Cultura de Paz,

1. Este documento forma parte de un proyecto más amplio, denominado "Familia y Medios de Comunicación", mismo que ha sido financiado por el Consejo Nacional de Ciencia y Tecnología (Conacyt). También constituye parte de los esfuerzos que se desarrollan en FAMECOM. Una versión preliminar de este texto fue presentado en el $\mathrm{X}$ Encuentro Latinoamericano de Facultades de Comunicación Social (FELAFACS), celebrado del 23 al 26 de octubre del 2000 en Sao Paulo, Brasil.

2. Profesor-investigador, Facultad de Ciencias Políticas y Administración Pública, Universidad Autónoma del Estado de México. Maestro en Comunicación; coordinador Ejecutivo de la Red Iberoamericana de Investigación en Familia y Medios de Comunicación (FAMECOM).

3. A finales de 1997, la Asamblea General de la oNu aprobó que el año 2000 fuese declarado Año Internacional de la Cultura de Paz. A partir de entonces diversas organizaciones e instituciones han empezado a mirar las contribuciones del este campo mutidisciplinario.

4. En el año 1974 fue creado el Consejo Latinoamericano de Investigación de la Paz. 
para después enfilar algunas reflexiones sobre lo que puede hoy representar para las familias de América Latina el espacio íntimo, doméstico, cosmopolita, videolúdico $\mathrm{y}$ telecentrista en el que se ven tensados $\mathrm{y}$, muchas veces, rotos los ejes que deberían articular la construcción cotidiana de una cultura que promueva la paz.

\section{Qué es la Cultura de Paz}

Johan Galtung (1995) se ha constituido en uno de los principales teóricos en materia de estudios para la Paz y el Desarrollo. En las etapas previas a las contribuciones de Galtung, los estudios para la Paz se habían circunscrito esencialmente a los sucesos bélicos en distintas épocas y latitudes del planeta. Su cometido principal era tratar de buscar alternativas para operar negociaciones que llevaran al cese de las acciones bélicas y en consecuencia a la instauración de la Paz. Por ello, durante muchos años fueron asociados los estudios en este campo a lo que los propios especialistas denominaron Paz negativa, es decir, el cese de la guerra.

Hacia el año 1973, como parte de la agenda de los estudios que realizaba la International Peace Research Asociation (IPRA), son ampliados los estudios para la Paz, en tanto no sólo eran dedicados al estudio de la guerra, sino a otras formas de violencia e injusticia social como la pobreza, la desigualdad, la desnutrición la no garantía de los derechos humanos y la colonización, entre otros.

Durante los años noventa, en la denominada cuarta etapa de los estudios sobre la Paz (Martínez, 1999), se agregaron nuevos fundamentos a lo que ya se había logrado construir durante la década precedente, es decir, a los temas sobre violencia y guerra, armas nucleares, conflicto global, racismo, sexismo, clase y subdesarrollo, represión y derechos humanos, se adicionaron justicia económica, violencia contra las mujeres, violencia cultural y papel de las organizaciones supranacionales

Hoy, los estudios sobre la cultura de Paz transitan por un puente habitado por zonas iluminadas que nos han ayudado a mirar de otra forma lo que a muchos nos parecía un solo cajón, una sola etiqueta: la violencia directa y física, la guerra, el golpe, la mala palabra, el secuestro, el disparo, la detonación.

Estos trabajos interdisciplinarios también han puesto en tela de juicio su propia construcción del conocimiento, en tanto discuten las formas usadas para analizar, construir y deconstruir un discurso de "buenas intenciones" en torno al desarrollo, la pobreza o las necesidades humanas.

A pesar de que los trabajos sobre esta temática han avanzado mucho, especialistas como Vicenc Fisas (1998), continúan planteando la necesidad de atender y entender tres premisas fundamentales que vertebran el trabajo en este campo: 
1. La llamada cultura de paz ha de concebirse como "un proceso, un camino sin fin en el que la paz constituye una referencia muy ambiciosa que está en el horizonte de la humanidad, a la que queremos dirigirnos y que supone una transformación absoluta de cuanto hacemos en el mundo".

2. La perspectiva de la paz está cifrada sobre la necesidad de avanzar en el mejoramiento de la condición humana, y todo cuanto se haga a este respecto será una efectiva aportación a este campo.

3. El trabajo ha de empezar "en la detección de aquellos fenómenos, dinámicas, comportamientos y estructuras que niegan derechos y limitan las potencialidades de crecimiento de las personas y de las sociedades" (1998:19-20).

En tal sentido, mi intención es incursionar en aquellas dinámicas, comportamientos y estructuras que circundan, emergen, se reproducen y parecen nutrir a las atmósferas familiares, no sólo de cara a los medios de comunicación, sino también como consecuencia de amplios procesos socioeconómicos y demográficos que niegan derechos y limitan el desarrollo potencial de quienes conforman estos micromundos cotidianos.

\section{Breve definición de paz y violencia}

Galtung sostiene que "la paz es la ausencia de violencia" y aunque admite que no se trata de una definición propiamente dicha para arrojar luz sobre el concepto de paz, sí confiere un punto de referencia - hasta de uso común - para dejar enlazados dos términos: paz y violencia, de tal forma que ante la ausencia de violencia, se pueda afirmar la presencia de paz (1995:313). Se trata de una definición que se apoya en un proceso de sustracción y de antítesis. Y justamente a partir de aquí, el matemático y sociólogo Johan Galtung emprende una interesante taxonomía para distinguir seis dimensiones de la violencia.

A este respecto, lo que interesa señalar es la concepción general de la que parte Galtung para definir la violencia: "está presente cuando los seres humanos se ven influidos de tal manera que sus realizaciones efectivas, somáticas y mentales, están por debajo de sus realizaciones potenciales" (1995:314). Con base en ello, el autor expone cada una de las distinciones de la violencia: de la violencia física a la psicológica; del enfoque negativo a la aproximación positiva; de la violencia con objeto a la que no precisa de ninguno para su operación; de la personal o directa a la violencia estructural o indirecta; de la violencia deliberada a la no intencional y de la 
manifiesta a la latente. El autor invita a continuar con la indagación y plantea que puede haber otras dimensiones de la violencia y que por ende éstas constituyan "ataduras" para que los seres humanos se desarrollen por debajo de sus realizaciones potenciales.

Mi punto de vista es que en el ámbito de los medios de comunicación y el micromundo familiar, se tejen y destejen cotidianamente muchas de las dimensiones de la violencia a las que refiere Galtung, aunque mayoritariamente nos hemos ocupado de los tipos de violencia física, psicológica, con objeto, personal y de tipo deliberado. Por ello, se han expresado - y con razón- preocupaciones en torno al contenido violento de géneros como las caricaturas, las películas de acción, las telenovelas; más recientemente los talk show, los videojuegos y algunos géneros musicales que suelen llegar a las audiencias juveniles. Muchos de estos programas, portadores de comportamientos física y psicoloógicamente violentos, son reprobados por algunos sectores de la población adulta en tanto se teme o se afirma que generan, reproducen o hacen germinar una sociedad cada vez más descompuesta. También se ha puesto de manifiesto la violencia intrafamiliar, referida más específicamente como un tipo de violencia física, de maltrato infantil o adulto (particularmente hacia las mujeres) y de marginación o imposición de reglas que permiten a unos el ejercicio de sus libertades y/o derechos y limitan a otras por el sólo hecho de ser mujeres.

Si para mal, todo ello ocurre y se desgrana en la vida cotidiana de muchas familias de América Latina, también es necesario dirigir la mirada hacia otras dimensiones de la violencia, particularmente la de tipo estructural o indirecta, por cuanto a partir de ella cobran mayor o menor relieve otros tipos o distinciones de violencia que actúan en la vida cotidiana de las familias.

\section{Violencia estructural}

Se trata de la cuarta distinción que formula Galtung, y en la que el autor nos coloca frente a la siguiente interrogante: Al no haber un actor o persona que "aparezca" en la escena cometiendo la conducta violenta, ¿se puede presumir o no que hay violencia? ¿Qué sucedería cuando tal acto violento no puede ser atribuido a nadie en particular (individuo, grupos, instituciones)? Este tipo de violencia permite incluir referentes como la desigualdad económica, la imposibilidad de conseguir empleo, la no-incursión o continuación en el sistema educativo, el no-acceso a los beneficios que proporcionan las telecomunicaciones y la microelectrónica, el impedimento para 
recibir los servicios de salud necesarios o los nutrientes diarios que se requieren para vivir y mantener un cuerpo saludable.

Cada una de estas "ausencias", por un lado, limita el desarrollo pleno de las realizaciones efectivas, somáticas y mentales de muchos de los seres humanos en América Latina y deja por debajo sus realizaciones potenciales. Por otra parte, es claro que para la mayoría de las personas no resulta fácil identificar a un actor, persona o institución que esté impidiendo el acceso a estos beneficios o servicios pero no por ello se deja de ejercer, precisamente, la violencia de tipo estructural.

A este respecto, demos un breve y selectivo recorrido por la geografía de América Latina y pasemos lista por las principales formas de representación de la violencia estructural. A la par, formularé algunas reflexiones en torno a las implicaciones de tipo de violencia para el mundo de las familias mediáticas.

\section{América Latina a través de algunas cifras básicas}

En la tabla que se muestra enseguida, se puede apreciar una selección de países de América Latina sobre los que formularé algunos comentarios y reflexiones. Como se puede apreciar, dicha selección operó sobre la base de dejar a un lado los países de habla inglesa que pueblan el continente, por considerarlos que operan con otro perfil y bases estructurales e históricas distintas. Asimismo, el orden en el que aparecen corresponde a la intención de ofrecer un recorrido de norte a sur.

Más de 330 millones de personas integramos estos 19 países de América Latina. Excepto Guatemala y Honduras, poco más de la mitad de la población vive en localidades urbanas pero hay casos como Venezuela y Uruguay en la que nueve de cada diez habitantes viven en zonas urbanas. Si bien es cierto que a partir de la década de los años cuarenta, en la mayor parte de los países del continente se observó el inicio del éxodo del campo hacia las ciudades, es hasta entrada la década de los sesenta cuando se aprecian de manera inexorable estas mutaciones en la población.

El hecho de que vivan más familias en zonas urbanas que en atmósferas rurales, fuera de todo romanticismo en torno a la vida campestre, deja en claro que la vida cotidiana rural se torna más precaria que en las zonas urbanas. Allí, en esa ruralidad, es donde más estragos hacen las carencias y las limitaciones para acceder a servicios de salud, educación, empleo, nutrientes y acceso a los servicios de telecomunicaciones (BID, 1998). Podemos imaginar una fuerte proporción de familias centroamericanas, dominicanas, ecuatorianas, bolivianas y paraguayas, que por su topografia están condenadas a resentir con mayor crudeza los efectos de la violencia 


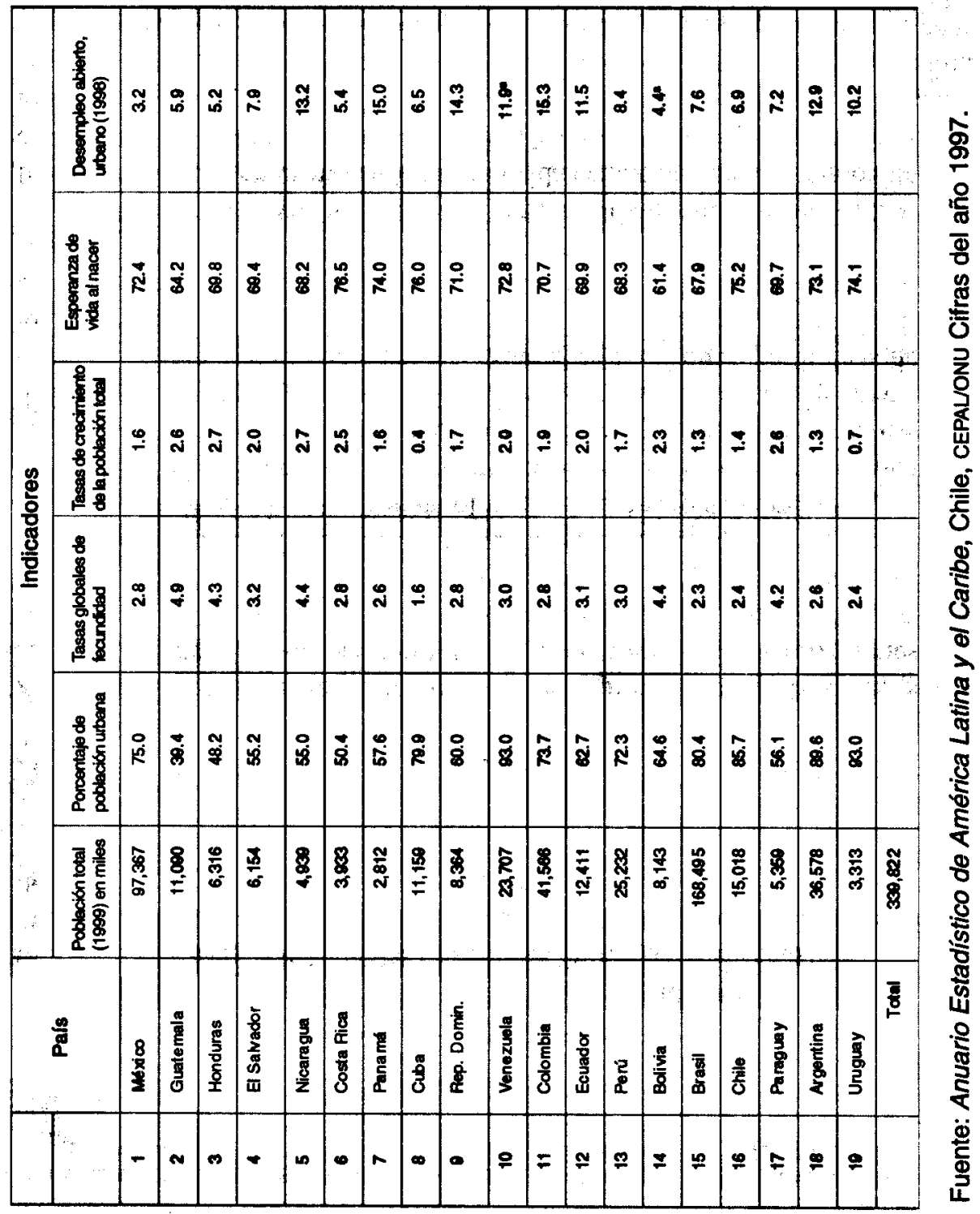


estructural. Pero el remedio no está, como ha querido parecer, en impulsar la urbanización de zonas rurales o en alentar los flujos migratorios campo-ciudad. Por el contrario, se trata de emprender e impulsar políticas sociales que hagan posible la vida digna tanto en las ciudades como en las localidades rurales, a fin de ofrecer un trato por igual a las familias, sin distingo de hábitat.

\section{Estructura familiar y (des)empleo, otra forma de violencia}

El tamaño de las familias se ha visto considerablemente disminuido en las últimas dos décadas en la mayor parte de América Latina. ${ }^{5}$ Para lograrlo, principalmente en las zonas urbanas, a través de políticas de planificación familiar, ha sido "dominado" el cuerpo de las mujeres y muy marginalmente el de los varones para que sólo tengan uno o dos vástagos y después, el resto de su vida productiva, la pareja fundante o alguno de los cónyuges ha de empeñar su fuerza productiva para proveer de los mejores bienes y servicios a su mundo familiar. Es decir, aun cuando durante varios años las políticas de planificación familiar nos vendieron a la mayor parte de los países latinoamericanos que debíamos tener "pocos hijos para darles mucho", la cruda realidad nos muestra que eso no bastó ni se cumplió la fantasía que rezaba el eslogan, porque paralelamente fueron disminuyendo o de plano desaparecieron muchos programas de protección y desarrollo social que los gobiernos aplicaban a la población.

Hoy, muchos padres y madres de familia de la América Latina que han logrado conservar su empleo, tienen en su agenda cotidiana la búsqueda de servicios de salud, de educación, vivienda, de recreación y de acceso a los servicios que proveen las telecomunicaciones y la microelectrónica, porque los gobiernos han dejado cómodamente de atender este tipo de servicios, con la calidad, eficiencia, efectividad y cobertura necesarias como para favorecer el desarrollo individual y colectivo. A cambio, lo han dejado en manos de las empresas y al libre juego de la oferta y la demanda. Ahora, la responsabilidad está en ese micromundo de las familias y no en los gobiernos o en el ámbito social y colectivo. Por ello, amen de lo que esto representa en el tema de la violencia estructural, se ha acrecentado una cultura individua-

5. Hay que destacar que me estoy refiriendo a la tendencia que muestra el continente, pues cuando se hacen procesamientos más desagregados se encuentra que las familias de bajos ingresos reportan un tamaño promedio de 6.3 miembros, en contraste con las familias que pertenecen al decil superior -referido por sus ingresos económicos- en los que están constituidos por un total de cuatro miembros (BID, 1998: 71). 
lista que sólo parece erigir planes, proyectos y acciones en y para una familia en particular, dejando al costado cualquier reflexión, política o preocupación de índole más colectivo.

A este respecto, vale señalar que algunas de las ideas que recientemente se han manejado - a través de los medios de comunicación - en las campañas políticas de los gobernantes, cifran su eje persuasivo sobre el ofrecimiento de acciones y políticas que redunden de manera más inmediata en beneficios del ámbito familiar o individual, como si la sociedad fuese un estadio inexistente o sin importancia.

Hasta aquí hemos partido del supuesto de que todas los padres y madres de familia latinoamericanos tienen acceso a uno de los derechos fundamentales para favorecer no sólo la existencia sino una vida digna: el empleo y la consecuente remuneración. Sin el ingreso económico suficiente, la satisfacción de necesidades elementales como alimentación, salud, vivienda y educación, se ponen en peligro y por ende la violencia estructural se acrecienta en la vida de las personas. Para el año 1998, las tasas de desempleo en los países seleccionados oscilaban entre $3.2 \mathrm{y}$ 15.0. Amen de recordar que la visión de los economistas deja mucho qué desear en torno a lo que consideran el desempleo abierto o, su contraparte, el empleo, hay que destacar y recuperar nuestra sensibilidad cotidiana para imaginar la crudeza que significa no tener empleo. En países como Nicaragua, Panamá, República Dominicana, Venezuela, Colombia, Ecuador, Argentina y Uruguay, durante el año que se refiere, la tasa rebasó los diez puntos. ¿Qué hacen para sobrevivir? ¿Cómo se ven trastocados procesos vitales y cotidianos como la alimentación, la vivienda, la salud y la educación, cuando pasan amplios periodos de sus vidas sin encontrar empleo? Más aún, ¿cómo enfrentan y reconceptualizan la vida a partir de que llegan - no pocos padres o madres de familia - a la conclusión de que no encontrarán empleo alguno? ¿Cuáles son las estrategias de supervivencia que trazan para enfrentar este desafio y las trayectorias de vida que se dibujan? ¿Cómo viven y padecen, a partir de entonces, con más agudeza la violencia estructural y qué otras violencias se edifican o recrean? ¿Con qué encono y hasta dónde?

Desde luego, una serie de interrogantes que nos llevan a la necesidad de reconceptualizar a las familias más allá de simples descripciones y denominaciones que se han empleado en los estudios que versan sobre familia y medios de comunicación. Apenas hemos atinado a describir a las familias sobre la base de su estructura: conyugal nuclear, ampliada, monoparental o recompuesta; sobre el eje de su dinámica; con respecto a su radicación: rural, urbana o semirubana o bien en torno a su nivel socioeconómico, encapsulado en categorías que huelen a eufemismo: nivel alto, medio o bajo. 
Hemos dejado en el camino el drama y la violencia que implica tanto la vida cotidiana de las familias como las condiciones particulares que representa el hecho de estar atrapado en la blanda categoría de nivel socioeconómico "bajo". Deberíamos intentar una mejor comprensión de las formas en que se presenta la violencia en familias de distintos estratos socioeconómicos porque no sólo el dramatismo acompaña a los que viven en la pobreza extrema sino también y con otros códigos a los muy ricos. Tendríamos que intentar un mejor análisis de lo que significan las condiciones de conyugalidad, no sólo las nucleares sino incluyendo otro tipo de estructuras que a pasos agigantados avanzan en otras tipologías y trayectorias de vida familiar.

En suma, antes de hacer entrar en la escena a los medios de comunicación, requerimos de una mejor comprensión de las atmósferas familiares. En varios países de América Latina, a pesar de las transformaciones socioculturales que reflejan los datos sobre hogares y familias, aún se sostiene que la familia debe estar encapsulada en la estructura conyugal-heterosexual nuclear (madre, padre e hijos compartiendo una casa) y que esta composición es el estado ideal para todas las familias, en la que por añadidura el jefe de la familia se espera que sea el cónyuge masculino. Si bien es cierto que "entre el 70 y 90 por ciento de los niños de América Latina viven en familias nucleares o grupos familiares más amplios" (BID, 1998:72), no debemos olvidar que en países como el Salvador, Venezuela, Panamá y Honduras, cerca del 30 por ciento de los niños ubicados en los tres deciles más bajos de ingresos viven en hogares encabezados por una sola persona (BID, 1998). Un dato más en torno a la participación y orquestación que tienen las mujeres en el ámbito familiar. En países como Nicaragua, Panamá, Puerto Rico, República Dominicana, Uruguay y Venezuela, el porcentaje de hogares encabezados por mujeres -no necesariamente monoparentales - se mueve en el rango: 21 al 25 por ciento respecto al total (Naciones Unidas, 1995). Es decir, aún cuando la vida de las personas traza otro curso o trayectoria, la narrativa dominante continúa manteniéndose como referente idealizado y los mismos protagonistas de las historias familiares se encargan de marcar, marginar o mantener encriptadas las distancias o desviaciones que guardan respecto a la idealización conyugal nuclear y heterosexual.

A este respecto, también hay que señalar —como lo comenta Francis Fukuyama- que las nuevas estructuras familiares también responden a otra serie de mutaciones en las que la familia nuclear muestra un creciente declive que dio inicio, para la mayor parte de Occidente, en los años setenta y ochenta, pues la gente empezó a contraer nupcias más tardíamente, a seguir casada menos tiempo y a no volverse a casar nuevamente (2000). También han crecido de manera notoria el número de nacimientos fuera de institución matrimonial, dando lugar a otras estruc- 
turas familiares, de las que parece que nos ocupamos poco en el campo de la investigación sobre familia y medios de comunicación.

\section{Vejez y violencia}

Veamos un indicador más. La esperanza de vida en América Latina ha rebasado los 60 años, para el caso de Bolivia, aunque hay países mejor colocados como Uruguay, Argentina, Chile y Cuba, pues oscilan entre 73 y 76 años (BID, 1998). Este dato alentador también genera una interrogante que desafía muchas realidades familiares ¿Hasta qué punto estamos preparados - actitudinal y comportamentalmentepara hacernos cargo y cuidar a nuestros viejos? - A quienes también eufemísticamente hemos dado en llamar personas de la tercera edad. ¿Qué tiempo nuestro les destinamos a los ancianos, en la vorágine de la vida cotidiana y mediática que lo único que parece instaurar es la cultura del segundo y, en palabras de Gilles Lipovetsky, el imperativo de la juventud que obliga a toda costa a "permanecer joven, no envejecer" (1996:62) ¿Cómo se mira devastado ese narcisismo al que precipitadamente hemos hecho llegar a los viejos desde nuestra cultura mediática, sin que tengamos tiempo ni voluntad alguna para hacerles - cuando hay condiciones económicas suficientes - la vida más tolerable y digna? No hay tiempo. Resultan demasiado lerdos(as), semisordos(as) y necios(as) para un cuerpo que apenas inicia y que vive de imágenes y que no es capaz de mirar al que está al łado y en franco declive. Pero presumimos, cual disonancia cognitiva, de la edad de nuestros padres o abuelos y de la esperanza de vida que reportan las estadísticas nacionales.

\section{Dinámica familiar y trayectorias}

Permítanme exponer un par de características más. La primera gira en torno a la dinámica familiar. Dicha cualidad, según la narrativa social (Langellier y Peterson, 1997), debe estar articulada con ingredientes como el amor, la comprensión, el apoyo mutuo, el encuentro pasional entre los cónyuges, la atención, la calidez y una positiva pauta comunicacional capaz de resolver cualquier conflicto incipiente, profundo o grave entre los miembros de la familia. La segunda se refiere al curso de vida o trayectoria. ${ }^{6}$ A este respecto, es frecuente que imaginemos - y que investi-

6. En el campo de los estudios sobre familia, una gran cantidad de autores se han sumado al concepto "ciclo de vida"; nosotros hemos optado por otro más amplio y dinámico a la vez, el de curso o trayectoria de vida. En otro trabajo discutimos las ventajas de este concepto (Guadarrama, 2000). 
guemos en el campo de la comunicación- familias atrapadas "normalmente" en sus dos primeras fases: la inicial y/o la intermedia (Steinglass, 1993) es decir, suponemos que las familias se constituyen como tales sólo cuando tienen hijos e hijas pequeñas o cuando éstos arriban a la adolescencia o a la juventud.

Trayectorias familiares como el escalonamiento entre hijos e hijas por segundas nupcias o uniones; por recomposiciones de pareja; por adopciones tardías o tempranas; por separaciones, divorcios o fallecimiento de alguno de los cónyuges; por alargamiento de la adolescencia; por prácticas sexuales homo y/o bisexuales; por soledades y cambios estructurales que se presentan ante una vida más longeva por parte de alguno de los cónyuges de la pareja de base; por vástagos con problemas de salud como el síndrome de Down, la hemiplejía, la drogadicción, la parálisis cerebral o la discapacidad fisica o mental, constituyen referentes, discursos y cursos de vida familiar que sólo marginalmente han ocupado un lugar en la narrativa social. Pero de mayor preocupación es que dichas trayectorias y formas de vida no hayan conquistado su lugar en la interacción poligonal que las familias establecen con los medios de comunicación. Tal parece que los dedicados a este tema no hemos logrado escapar a nuestra condición de clase y por ende hemos orientamos nuestros esfuerzos a explorar sólo determinados perfiles familiares correspondientes, en mayor o menor medida, con nuestras concepciones de lo que debe constituir el mundo familiar.

Entre tanto, nos hemos refugiado precipitadamente en el análisis mediático de la violencia física, psicológica, con objetos e intencional que se desgrana día a día en los medios de comunicación. Nos hemos enfrascado en el estudio de la relación cotidiana y poligonal que las familias establecen con los medios. Es claro que ha sido más fácil ver cierto tipo de violencia y hasta contemplarla en la pantalla catódica; en los videojuegos, en la prensa escrita y en las páginas que deambulan por la internet. Ha sido dificil virar nuestra mirada atenta para identificar y desmenuzar la violencia que todos los días deambula en el tejido social y en el mundo familiar inmediato. Acaso será porque está tan adentro que ya no nos duele más; que hemos aprendido a tolerarla y a vivir plácidamente con ella.

\section{Bibliografía}

Banco Interamericano de Desarrollo (1998), América Latina frente a la desigualdad, New York: BID.

CEPAL (1997), Anuario Estadístico de América Latina y el Caribe, Chile: CEPAL/ ONU. 
Fisas, Vicenc (1998), Cultura de paz y gestión de conflictos. Barcelona: Icaria/ Antrazyt/Ediciones Unesco.

Fukumya, Francis (2000), La gran ruptura. Naturaleza humana y reconstrucción del orden social. Barcelona, Ediciones B, Grupo Z.

Galtung, Johan (1995), Investigaciones Teóricas. Sociedad y cultura contemporáneas. España, Tecnós.

Guadarrama Rico, Luis Alfonso (2000), “Apuntes metodológicos para investigar familias y medios de comunicación". México, UAEM (En prensa).

Lipovetsky, Gilles (1996), La era del vacio. Ensayos sobre el individualismo contemporáneo. Barcelona, Anagrama.

Martínez Guzmán (1999). "Los estudios epistemológicos de la investigación y los estudios para la paz". España: Universitat Jaume I de Castellón [Mecanograma]. Naciones Unidas (1995). Situación de la mujer en el mundo, 1995. Tendencias $y$ estadisticas. Nueva York, Naciones Unidas.

Steinglass, Peter, et al. (1993), La familia alcohólica. España, Gedisa. 